\title{
EFEKTIVITAS PERINEUM MASSAGE DENGAN MODIFIKASI HANDS- OFF DAN PERINEUM MASSAGE DENGAN MODIFIKASI HANDS-ON TERHADAP RUPTUR PERINEUM DI BPM KOTA PEMATANGSIANTAR
}

\author{
Juliani Purba, Tengku Sri Wahyuni \\ Prodi Kebidanan Pematangsiantar
}

\begin{abstract}
ABSTRAK
Berbagai metode telah dilakukan untuk mengurangi terjadinya ruptur perineum, baik sejak kehamilan maupun pada proses persalinan. Beberapa hasil penelitian di berbagai daerah di Indonesia tentang perineum massage mendapatkan hasil yang signifikan terhadap penurunan kejadian ruptur perineum. Pada masa persalinan hasil penelitian juga mendapatkan perbedaan antara persalinan dengan hands on atau hands off terhadap kejadian keutuhan perineum. Penelitian ini bertujuan untuk mengetahui perbandingan efektifitas perineum massage dengan modifikasi hands-off dan perineum massage dengan hands- on terhadap ruptur perineum pada primipara di BPM Kota Pematangsiantar. Jenis penelitian quasi experiment design dengan analisis data yang digunakan Chi-Square. Berdasarkan hasil uji statistic dengan menggunakan Chi-Square diketahui bahwa terdapat perbedaan yang signifikan antara perineum massage dengan modifikasi hands-off dan perineum massage dengan modifikasi hands-on terhadap ruptur perineum yaitu sig(2-tailled $)=0,002<$ 0,05 , maka dari penelitian ini diketahui bahwa lebih efektif perineum massage dengan modifikasi hands-off daripada perineum massage dengan modifikasi hands-on untuk mencegah terjadinya ruptur perineum pada ibu primipara di BPM Kota Pematangsiantar.
\end{abstract}

\section{Kata Kunci: Perineum Massage, Hands-off, Hands-on, Rupture perineum, Primipara}

\section{PENDAHULUAN}

Hasil SDKI 2012 angka kematian ibu kembali naik dari 228 per 100.000 kelahiran hidup pada SDKI 2007 menjadi 359 per 100.000 kelahiran hidup, dan hasil ini masih sangat jauh untuk mencapai target MDGs tahun 2015 sebesar 102 per 100.000 kelahiran hidup. Penyebab terbesar kematian ibu selama 2010-2013 adalah perdarahan, meskipun data cakupan pertolongan persalinan oleh tenaga kesehatan secara Nasional sampai tahun 2013 sudah mencapai $90,88 \%$. Angka cakupan pertolongan persalinan di Provinsi Sumatera Utara lebih rendah dari cakupan Nasional yakni 81,71\% (Kemenkes RI, 2014).

Berbagai metode telah dilakukan untuk mengurangi terjadinya ruptur perineum, baik sejak kehamilan maupun pada proses persalinan. Perineum massage adalah salah satu upaya yang dapat dilakukan sejak kehamilan.Perineum massage adalah tehnik memijat perineum pada saat hamil atau beberapa minggu sebelum melahirkan guna meningkatkan perubahanhormonal yang melembutkan jaringan ikat, sehingga jaringan perineum lebih elastik dan lebih mudah meregang (Aprilia, 2010).

Beberapa hasil penelitian di berbagai daerah di Indonesia tentang perineum massage mendapatkan hasil yang signifikan terhadap penurunan kejadian ruptur perineum. Penelitian Savitri di Bengkulu pada tahun 2014 mendapatkan ada pengaruh perineum massage pada primigravida dengan kejadian ruptur perineum pada saat persalinan dengan nilai $\mathrm{p}=0,02$. Hasil yang sama juga diperoleh Kundarti di Kediri dengan nilai $p=0,00$; $R R=$
2,26; $95 \%$ CI= 1,50- 4,73 dan hasil penelitian Suharni juga mendapatkan hasil yang sama (Savitri, 2015; Kundarti, 2014; Suharni, 2006).

Hasil penelitian di India mendapatkan tidak ada perbedaan antara persalinan dengan hands on atau hands off terhadap kejadian keutuhan perineum dengan nilai $\mathrm{p}=$ 0,74 , ruptur perineum tk. I dengan nilai $\mathrm{p}=0,17$ dan ruptur perineum tk. II dengan nilai $\mathrm{p}=0,35$. Namun demikian untuk kejadian ruptur perineum tk. III, tindakan episiotomi dan trauma pada daerah periuretra pada persalinan hands off lebih signifikan dibandingkan dengan hands on dengan nilai $\mathrm{p}=0,01 ; \mathrm{p}=0,003$ dan $\mathrm{p}=0,01$ (Rozita, 2014). Hasil penelitian di Iran juga mendapatkan tehnik hands-on lebih tinggi menyebabkan tindakan episiotomi dibandingkan dengan tehnik hands- off pada kala II persalinan dengan persentase masing-masing $84 \%$ dan $40 \%$ serta nilai $\mathrm{p}=0,001$ (Foroughipour, 2010).

Hasil survey awal yang telah dilakukan pada bulan September 2015 di 5 Bidan Praktek Mandiri di kota Pematangsiantar dengan jumlah rata-rata pertolongan persalinan 4-5 kasus/ bulan penerapan pijat perineum belum pernah dilakukan dan untuk melahirkan kepala pada kala II persalinan hanya menggunakan manuver Ritgen/ hands-on. Hasil suvey tersebut juga menemukan angka kejadian ruptur perineum mencapai $83 \%$ dan belum pernah dievaluasi nyeri pasca persalinan yang dapat dijadikan bahan refleksi untuk memperbaiki asuhan yang diberikan. 


\section{METODE PENELITIAN}

Pada penelitian ini jenis penelitian yang digunakan quasi experiment design. Dalam pendekatan ini tidak menggunakan sistem randomisasi namun pendekatan ini tidak memiliki ciri-ciri rancangan eksperimen sebenarnya, karena variabel- varibel yang seharusnya dikontrol atau dimanipulasi sulit dilakukan (Notoadmodjo, 2010). Sampel penelitian masing-masing 20 orang ibu hamil primigravida yang memenuhi kriteria inklusi. Sejak usia kehamilan 35 minggu di sudah dilakukan perineum massage, dan ketika persalinan dilakukan metode hands-off atau hand-on. Tehnik pengambilan sampel secara accidental sampling yang di ambill pada bulan April - Juni 2016.

\section{HASIL DAN PEMBAHASAN}

\section{HASIL PENELITIAN}

Penelitian ini dilakukan pada 40 responden yang memenuhi kriteria inklusi dan ekslusi yang terdiri. Responden dibagi menjadi dua kelompok yang mendapat perlakuan hands on dan perlakuan hands off masing- masing 20 responden.

Tabel 1. Karakteristik responden berdasarkan Hands-Off dan Hands-On

\begin{tabular}{|c|c|c|c|c|c|}
\hline \multirow[t]{3}{*}{ No. } & \multirow[t]{3}{*}{ Karakteristik } & \multicolumn{4}{|c|}{ Perlakuan } \\
\hline & & \multicolumn{2}{|c|}{ Hands-off } & \multicolumn{2}{|c|}{ Hands-on } \\
\hline & & $\mathbf{F}$ & $\%$ & $\mathbf{F}$ & $\%$ \\
\hline \multicolumn{6}{|c|}{ 1. Umur } \\
\hline & $<20$ Tahun & 1 & 10 & 12 & 60 \\
\hline & 20-35 Tahun & 19 & 90 & 8 & 40 \\
\hline \multicolumn{6}{|c|}{ 2. Berat Badan Lahir } \\
\hline & $<3 \mathrm{Kg}$ & 10 & 50 & 14 & 70 \\
\hline & $>3 \mathrm{Kg}$ & 10 & 50 & 6 & 30 \\
\hline \multicolumn{6}{|c|}{ 3. $\quad$ Rupture Perineum } \\
\hline & Derajat 1 & 11 & 55 & 2 & 10 \\
\hline & Derajat 2 & 9 & 45 & 18 & 90 \\
\hline
\end{tabular}

Berdasarkan hasil tabel 1 diketahui bahwa umur < 20 tahun pada kelompok perineum massage dengan modifikasi hands-off sebanyak 1 responden (10\%), umur 20-35 tahun sebanyak 19 responden (90\%), pada kelompok perineum massage dengan modifikasi hands-on pada umur < 20 tahun sebanyak 12 responden $(60 \%)$ dan umur 20-35 tahun sebanyak 8 responden (40\%).

Diketahui juga dari tabel 1 bahwa berat badan lahir < $3 \mathrm{Kg}$ pada kelompok perineum massage dengan modifikasi hands-off sebanyak 10 responden (50\%), sama dengan berat badan lahir $>3 \mathrm{Kg}$, pada kelompok perineum massage dengan modifikasi hands-on pada berat badan lahir $<3 \mathrm{Kg}$ sebanyak 14 responden $(70 \%)$ dan berat badan lahir $>3 \mathrm{Kg}$ sebanyak 6 responden $(30 \%)$.
Tabel 2. Karakteristik Responden berdasarkan derajat rupture perineum.

\begin{tabular}{|l|l|c|c|c|c|}
\hline \multirow{2}{*}{ No. Karakteristik } & \multicolumn{4}{|c|}{ Ruptur Perineum } \\
\cline { 3 - 6 } & & Derajat 1 & \multicolumn{2}{|c|}{ Derajat 2 } \\
\cline { 3 - 6 } & F & \% & F & \% \\
\hline 1. Umur & 2 & 15,4 & 11 & 84,6 \\
\hline 1. & $<20$ Tahun & 11 & 40,7 & 16 & 59,3 \\
\hline 2. & $20-35$ Tahun & 4 & 16,7 & 20 & 83,3 \\
\hline 2. Berat Badan Lahir \\
\hline 1. & $<3 \mathrm{Kg}$ & 9 & 56,2 & 7 & 43,8 \\
\hline 2. & $>3 \mathrm{Kg}$ &
\end{tabular}

Dari hasil tabel 2 diketahui bahwa ibu yang bersalin pada umur $<20$ tahun mengalami rupture perineum derajat 1 sebanyak 2 responden $(15,4 \%)$ sedangkan derahat 2 sebanyak 11 responden $(84,6 \%)$, dan umur 20-35 tahun terjadi rupture perineum derajat 1 sebanyak 11 responden $(40,7 \%)$ dan derajat 2 sebanyak 16 responden $(59,3 \%)$.

Tabel 2 juga menginformasikan babahwa ibu yang melahirkan dengan berat badan lahir $<3 \mathrm{Kg}$ mengalami rupture perineum derajat 1 sebanyak 4 responden $(16,7 \%)$ dan derahat 2 sebanyak 20 responden $(83,3 \%)$. Pada ibu- ibu yang melahirkan dengan berat badan lahir > $3 \mathrm{Kg}$ terjadi rupture perineum derajat 1 sebanyak 9 responden $(56,2 \%)$ dan derajat 2 sebanyak 7 responden $(43,8 \%)$.

Tabel. 3. Perbandingan Efektifitas Hands-Off dan Hands-on Terhadap Rupture Perineum pada Ibu Primipara Di BPM Kota Pematangsiantar

\begin{tabular}{|c|c|c|c|c|c|c|}
\hline \multirow{3}{*}{$\begin{array}{l}\mathbf{N} \\
\mathbf{0}\end{array}$} & \multirow{3}{*}{$\begin{array}{l}\text { Perineum } \\
\text { Massage }\end{array}$} & \multicolumn{4}{|c|}{ Ruptur Perineum } & \multirow{3}{*}{$\begin{array}{l}p= \\
\text { Value }\end{array}$} \\
\hline & & \multicolumn{2}{|c|}{ Derajat 1} & \multicolumn{2}{|c|}{ Derajat 2} & \\
\hline & & $\mathbf{f}$ & $\%$ & $\mathbf{f}$ & $\%$ & \\
\hline 1. & Hands-off & 11 & 55 & 9 & 45 & \multirow[t]{2}{*}{0,002} \\
\hline 2. & Hands-on & 2 & 10 & 18 & 90 & \\
\hline
\end{tabular}

Berdasarkan hasil pada tabel 3 diketahui perineum massage dengan modifikasi Hands-off mendapatkan hasil responden dengan rupture perineum derajat 1 sebanyak 11 responden $(55 \%)$ sementara dan perineum dengan modifikasi hands-on lebih banyak pada rupture perineum derajat 2 sebanyak 9 responden $(45 \%)$.

Hasil penelitian ini juga menginformasikan bahwa hands-off efektif untuk mencegah terjadinya ruptur perineum dengan hasil Sig. (2-tailed) $<0,05$ yaitu $0,002<$ 0,05 berarti terdapat perbedaan yang signifikan antara perineum massage dengan modifikasi Hands-off dengan perineum Massage dengan modifikasi Hands-on terhadap rupture perineum pada ibu primipara.

\section{PEMBAHASAN}

Sejak kehamilan maupun pada saat proses persalinan berbagai upaya telah dilakukan untuk mencegah terjadinya ruptur pada perineum. Terjadinya ruptur perineum erat kaitannya dengan persalinan primigravida, kala II yang terlalu lama, faktor bayi yang dilahirkan dan 
faktor gizi. Diyakini, semakin besar bayi yang dilahirkan dapat meningkatkan risiko terjadinya rupture perineum.

Pada penelitian ini untuk umur responden yang < 20 tahun lebih banyak yang mengalami ruptur perineum derajat 2 yakni 11 responden $(84,6 \%)$ sedangkan responden pada umur 20-35 tahun hanya $16(59,3 \%)$ yang mengalami rupture perineum derajat 2 . Hal ini sangat dimungkinkan karena usia responden yang masih terlalu muda untuk memulai proses reproduksinya. Masih ada organ reproduksi yang belum tumbuh/ berkembang dengan baik dibandingkan pada responden yang sudah berada pada usia reproduksi sehat.

Variabel berat bayi lahir tidak menujukan hasil yang sesuai secara teoritis. Responden dengan bayi berat lahir > $3 \mathrm{~kg}$ hanya 7 (43,8\%) yang mengalami rupture perineum derajat 2. Sedangkan responden dengan bayi berat lahir $<3 \mathrm{~kg}$ mencapai $20(83,3 \%)$ mengalami rupture perineum derajat 2 . Selain faktor berat lahir bayi stautus gizi ibu juga berpengaruh terhadap kejadian rupture perineum dan status gizi ibu tidak diteliti dalam penelitian ini. Posisi persalinan, penggunaan oksitosin, tenaga dan tehnik ibu ketika meneran, dan adanya dukungan orang mungkin mempunyai andil untuk terjadinya rupture perineum dibandingkan dengan metode hands-off atau hands on.

Hasil penelitian ini mendapatkan bahwa responden yang mendapatkan perineum massage dengan modifikasi Hands-off lebih tinggi mengalami ruptur perineum derajat 1 yakni 11 responden $(55 \%)$ sedangkan responden yang mendapatkan perineum massage dengan modifikasi Hands-on hanya 2 responden (10\%). Penelitian Costa di Brazil menemukan hasil yang berbeda, pada kedua kelompok responden dengan metode hands-off dan handson $82,2 \%$ berbanding $82,7 \%$ derajat 1 dan $17,8 \%$ dibandingkan $17,3 \%$ ruptur perineum derajat 2 .

Hasil uji statistik dengan menggunakan Chi-Square diketahui bahwa untuk mencegah terjadinya rupture perineum pada primipara modifiksai hands-off lebih efektif dengan hasil Sig. (2-tailed) 0,002 $<0,05$ dibandingkan perineum Massage dengan modifikasi Hands-on. Rozita (2014) dalam hasil penelitiannya mendapatkan hasil tidak ada perbedaan yang signifikan yang terlihat pada laserasi perineum $(\mathrm{p}=0,74)$ di antara kedua kelompok (hands-off dan hands-on).. Laserasi yang paling umum terjadi pada kedua kelompok tersebut adalah rupture perineum tingkat pertama. Ruptur perineuma derajat 3 lebih sedikit terjadi pada kelompok hands-off dibandingkan dengan hands-on $(\mathrm{p}=0,01)$ begitupula dengan tindakan episiotomi dengan $(\mathrm{p}=0,003)$.

Pada hasil penelitian ini berbeda dengan penelitian di Brazil maupun India mungkin dikarenakan pencegahan ruptur perineum telah dilakukan sejak masa kehamilan. Bagi ibu yang akan melahirkan rasa takut dan cemas saat persalinan merupakan hal yang wajar. Terjadinya robekan jalan lahir/ perineum juga merupakan sumber kecemasan ibu. Dengan pijat perineum diharapkan kecemasan ibu dapat berkurang karena selama hamil otototot disekitar perineum yang banyak mengandung jaringan ikat serta kolagen yang bersifat elastik semakin menjadi alastis (Chapman, 2006).
Hasil penelitian yang dilakukan Trochez (2011) di England terhadap bidan yang bekerja di unit-unit maternitas mendapatkan bahwa 299 responden (49,3\%) menolong persalinan dengan metode hands-off sedangkan 295 responden $(48,6 \%)$ menggunakan metode hands-on. Di Indonesia dalam masa pendidikan maupun dalam pelatihan Asuhan Persalinan Normal (APN) bidan diajarkan untuk melakukan pertolongan persalinan dengan metode hands-on. Ketika kepala crowning dengan handson diharapkan akan membantu mengendalikan kepala ketika ekspulsi sehingga tidak terlalu cepat.

\section{KESIMPULAN}

1. Umur < 20 tahun lebih banyak mengalami ruptur perineum derajat 2 sebanyak 11 responden $(84,6 \%)$ sedangkan umur 20-35 tahun rupture perineum derajat 2 sebanyak 16 responden $(59,3 \%)$.

2. Ibu dengan $\mathrm{BBL}<3 \mathrm{~kg}$ dengan ruptur derajat 1 sebanyak 4 responden $(16,7 \%)$ sedangkan ibu dengan $\mathrm{BBL}>3 \mathrm{~kg}$ dengan rupture derajat 1 sebanyak 9 responden $(56,2 \%)$.

3. Perineum massage dengan modifikasi hands-off dan perineum massage dengan hands-on lebih efektif untuk mencegah ruptur perineum pada primipara yaitu sig(2-tailled $)=0,002<0,05$.

\section{SARAN}

Diharapkan kepada petugas Kesehatan khususnya BPM yang ada di Kota Pematangsiantar dapat mengoptimalkan penyuluhan tentang persiapan persalinan terutama cara mencegah ruptur perineum pada proses persalinan.

Penelitian lanjutan perlu dilakukan dengan jumlah sampel yang lebih besar dan variable penelitian yang lebih banyak sehingga dapat dijadikan evidence based untuk memberikan asuhan persalinan yang lebih baik.

\section{DAFTAR PUSTAKA}

Aprillia Y, 2010. Rileks nyaman dan aman saat hamil dan melahirkan. Jakarta: Gagas Media

Beckmann MM, Garret AJ, 2009. Antenatal perineal massage for reducing perineal trauma. Cochrane Databasse of systematic review, Issue 1.DOI 10.1002/14651858.CD005123

Berghella V, 2012. Obstetric Evidence- Based Guidelines, Second Editioan.. Series in Maternal-Fetal Medicine.New York London. Informa Health Care.

Costa ASC, Riesco MLG, 2006. A Comparison of "Hands Off" Versus "Hands On Techniques for Decreasing Perineal Lacerations During Birth. J Midwifery Womens Health

Cunningham, F, 2013. Obstetri Williams, edisi ke-21. Vol. 1. Profitasari, editor edisi bahasa Indonesia. Jakarta: EGC

Danuatmaja B, 2004. Persalinan normal tanpa rasa sakit. Jakarta: Puspa Swarna. 
Departemen Kesehatan, 2008. Asuhan Persalinan Normal. Jakarta.

Foroughipour A,Firuzeh F,Ghahiri A, VajiheNorbakhsh V,Heidari T, 2011. The effectof perineal control with hands-on and hand-poised methods on perineal trauma and delivery outcome.JResMedSci/August2011;Vol16,No 8.

Herdiana , Trirejeki, 2007. Tips pijat perineum, Jakarta: EGC

Kemenkes RI, 2014. Infodatin Mother Day: Situasi Kesehatan Ibu. Pusat data dan Informasi Kementerian Kesehatan RI.

Kundarti FI, Estuning D, Budiarti T, 2014. Pengaruh pemijatan perineum pada ibu primigravida terhadap robekan perineum saat persalinan. Jurnal Gema Bidan Indonesia, Vol III, No.1.

Mongan, Marie FM, 2007. Hypno birthing: metode melahirkan secara aman, mudah, dan nyaman. Jakarta: BIP.

Nolan, M. 2003. Kehamilan dan Melahirkan. Jakarta: Rineka Cipta

Notoatmodjo S, 2010. Metodologi Penelitian Kesehatan. Jakarta: RinekaCipta.

Rozita R, Sussan S, Huak CY,Sharif NH, 2014. A Comparison of the "Hands-Off" and "HandsOn” Methods to Reduce Perineal Lacerations :A Randomised Clinical Trial. The Journalof Obstetrics and Gynecology of India (NovemberDecember2014)64(6):425-429, DOI10.1007/s13224-014-0535-2

Oxorn H, 2010. Patologi dan fisiologi persalinan. Jakarta: Yayasan Essentia
Medika

Saifuddin, 2009.. Ilmu kebidanan. Jakarta :PT Bina Pustaka Sarwono Prawirohardjo

Savitri W, Ernawati, Yusefni E, 2015. Pengaruh pemijatan perineum pada primigravida terhadap kejadian rupture perineum saat persalinan di Bidan Praktek Mandiri di Kota Bengkulu. Jurnal Kesehatan Andalas, 4 (1).

Suharni, 2006. Pengaruh masase perineum masa ante natal terhadap rupture perineum pada primipara. Tesis: Fakultas Kedokteran Klinis Universitas Gadjah Mada, Yogyakarta.

Trochez R, Waterfield M, Freeman RM, 2011. $\underline{\text { Hands }}$ on or hands off the perineum: a survey of care of the perineum in labour (HOOPS). Int Urogynecol J. 2011 Oct;22(10):1279-85. doi: 10.1007/s00192-011-1454-8. Epub 2011 May 25.

Wiknjosastro H, 2009. Ilmu Kebidanan. Jakarta: Yayasan Bina Pustaka Sarwono Prawirohardjo. 